\title{
EDITORIAL
}

\section{Tercer Congreso Mundial de Infectología Pediátrica: Una fiesta a la que nadie debe faltar}

\author{
3rd WORLD CONGRESS OF PEDIATRIC INFECTIOUS DISEASES: \\ A PARTY THAT NOBODY CAN MISS
}

Entre el 19 y 23 de noviembre de este año se desarrollará en CasaPiedra el evento más significativo para la infectología chilena y latinoamericana de los últimos años: el III Congreso Mundial de Infectología Pediátrica. Este congreso constituye la actividad central de la Sociedad Mundial de Infectología Pediátrica, una verdadera "Federación” que reúne a las Sociedades Regionales de Estados Unidos de América, Europa, Asia, y Latinoamérica, cuyo presidente actual es Somsak Lolekha de Tailandia.

A casi ocho meses de su realización, y a pesar de los turbulentos momentos que vivimos, es muy satisfactorio poder compartir con ustedes la excelente acogida que hemos tenido de parte de muchos de los amigos de la comunidad infectológica pediátrica mundial. Contamos a la fecha con más de 70 expositores confirmados, provenientes de 27 diferentes países, la mayoría de los cuales son líderes de opinión en sus respectivas áreas, todo lo cual asegura un Programa Científico de primer nivel. Hemos trabajado arduamente para desarrollar un programa científico atractivo que se distribuirá en 21 simposios y 11 conferencias que abarcan los temas más relevantes en la actualidad. Además hemos estructurado 12 sesiones de "Meet the Professor" para que los asistentes puedan, en reuniones más pequeñas, interactuar con los líderes de opinión de su interés. Adicionalmente, y gracias a la excelente acogida por parte de la industria farmacéutica mundial, durante las horas de almuerzo de los tres días, y en otros horarios por confirmar, se desarrollarán simposios de la industria, de primer nivel académico como Uds. mismos podrán corroborar, al cual vendrán expositores de reconocimiento mundial. Esperamos contar con una asistencia superior a las 1500 personas entre infectólogos, pediatras, epidemiólogos y médicos generales de todo el mundo, especialmente de Chile y Latinoamérica.

El lema que hemos acuñado para el Congreso es: "La Infectología Pediátrica en el Mundo Global: Qué podemos aprender unos de otros". El mensaje que queremos trasmitir es que en el mundo del siglo 21, en donde las interacciones entre los más lejanos puntos de la tierra son posibles, todos, independientemente de nuestro nivel de desarrollo económicosocial, de investigación básico y/o clínica, estructura de sistemas de salud, formas de ejercer la medicina, etc., tenemos algo que aportar y compartir con los demás. Es por ello que en este III Congreso Mundial tendremos expositores de más de 25 países y esperamos, asistentes de aún un mayor número de países, dispuestos a compartir sus experiencias. Creemos que un evento de esta naturaleza debe ser aprovechado al máximo por la comunidad médica nacional. Tenemos la esperanza de que todos Uds. apoyen esta iniciativa e incentiven a los médicos chilenos a asistir. Esta es una oportunidad única no sólo de conocer en persona a los infectólogos pediatras de prestigio mundial, sino que, probablemente más importante, desarrollar esta interacción con médicos de las más remotas áreas del mundo. Seremos dueños de casa y como tal tendremos la oportunidad de demostrar la tradicional hospitali- 
dad que nos caracteriza, estaremos golpeando las puertas de muchos de Uds. para que nos ayuden, como también, para demostrar el nivel científico-médico en que nos desenvolvemos. Insto a todos Uds. a que postulen sus trabajos libres los cuales serán presentados en posters que tendrán un tiempo de dedicación exclusiva importante. El Comité Organizador seleccionará 5 a 10 trabajos presentados por investigadores chilenos de regiones para un subsidio de US\$ 200 para pasaje aéreo y/o estadía por 3 noches en el Hotel Kennedy. Este subsidio es posible gracias al aporte del "Programa de Apoyo a Congresos Científicos Internacionales en Chile" de CONICYT. Los beneficios de subsidios serán contactados a más tardar el 31 de septiembre. Trabajos seleccionados serán expuestos en forma oral y se han instaurado dos premios, "Premio III Congreso Mundial" y Premio Investigador Joven" con un atractivo estímulo monetario; las bases para presentar los resúmenes los encontrarán en la página WEB del congreso www.kenes.com/wspid, a la cual también pueden acceder a través de la página de la Sociedad.

Finalmente, no me queda más que agradecer la desinteresada labor y apoyo que hemos recibido desde un comienzo por parte de tantos amigos dentro y fuera de Chile así como de instituciones que han comprendido la relevancia del evento para nuestro país. Es este entusiasmo el que nos ha contagiado a trabajar más duro para que este III Congreso sea un éxito que deje huella. El apoyo comenzó por esta Sociedad y su Presidenta, María Elena Santolaya, primera auspiciadora del evento, seguido de la Sociedad Chilena de Pediatría, CONICYT, Ministerio de Educación, Ministerio de Salud, Intendencia y Alcaldía de Santiago para nombrar algunos, los Presidentes de PIDS of America, Richard Jacobs (activo) y Sheldon Kaplan (electo), SLIPE: Eduardo Suárez Catañeda, ESPID (Europa): Mieke Hoogkamp, y ASPID (Asia): Somsak Lolekha; reconocidos infectólogos pediatras como Ron Dagan, George McCracken, Steve Black, Xavier Saez-Llorens, Napoleón González-Saldaña, Larry Pickering, Stanley Plotkin, Carol Baker, Carla Odio, Heikki Peltola, por nombrar sólo a algunos de nuestros amigos infectólogos que nos han apoyado en forma irrestricta; un importante grupo de colegas nacionales que conforman el Comité Organizador, cuyo aporte es inevaluable, y la Industria Farmacéutica Internacional y Nacional que en gran medida, con escasas excepciones, han comprendido la trascendencia del evento y le han dado su apoyo. A todos un agradecimiento por la labor realizada que nos permite mirar con optimismo el futuro y vislumbrar que el III Congreso Mundial será realmente una fiesta de la infectología mundial.

Miguel O'Ryan G. 